\title{
A SEMISHRINKING BASIS WHICH IS NOT SHRINKING
}

\author{
J. R. RETHERFORD ${ }^{1}$
}

A Schauder basis $\left(x_{i}, f_{i}\right)$ for a Banach space $X$ is

(1) shrinking provided $\left(f_{i}\right)$ is a basis for $X^{*}$; and

(2) semishrinking provided $0<\inf _{n}\left\|x_{n}\right\| \leqq \sup _{n}\left\|x_{n}\right\|<+\infty$ and $\left(x_{n}\right)$ is weakly convergent to 0 .

A. Pełczynski and W. Szlenk [2], answering a question raised by I. Singer, constructed a Banach space with a semishrinking basis which was not shrinking. Their construction, while elegant, is very complicated. Our purpose here is to show that the space $(d)$ constructed by Davis and Dean $[1$, p. 214] has such a basis.

The space $(d)$ consists of those real sequences $a=\left(a_{i}\right)$ for which

$$
\|a\|=\sup _{p \in \mathcal{P}} \sum_{i=1}^{\infty} \frac{\left|a_{\rho(i)}\right|}{i}<+\infty
$$

where $P$ denotes the collection of all 1-1 maps from the positive integer $\omega$ into $\omega$. Davis and Dean $[1$, p. 214] have shown that the unit vectors $\left(e_{n}\right)$ form a semishrinking basis for $(d)$ (although their terminology is different). We show that $\left(e_{n}\right)$ is not shrinking.

Let $h_{n}=\sum_{i=1}^{n}(1 / i)$ and define $u_{n} \in(d)$ by $u_{n}=h_{n}^{-1} \sum_{=1}^{i} e_{i}$. Clearly $\left\|u_{n}\right\|=1$ for $n=1,2,3, \cdots$. Define a linear functional $F$ on $(d)$ by $F(x)=\sum_{i=1}^{\infty}\left(x_{i} / i\right)$ where $x=\left(x_{i}\right)$. By the definition of the norm on $(d)$ it follows that $F \in(d)^{*}$. Moreover, $F\left(\mathfrak{U}_{n}\right)=1$ for each $n$ and so $\left(\mathfrak{U}_{n}\right)$ does not converge weakly to 0 . However if $\left(f_{i}\right)$ denotes the coefficient functionals associated with $\left(e_{n}\right)$ then $\lim _{n \rightarrow \infty} f_{i}\left(\mathcal{U}_{n}\right)=\lim _{n \rightarrow \infty} h_{n}^{-1}=0$. Thus by a theorem of Wilansky [4] (see also [3, property $(E)]$ ) $\left(e_{n}\right)$ is not shrinking.

\section{BibliograPHy}

1. W. J. Davis and D. W. Dean, The direct sum of Banach spaces with respect to a basis, Studia Math. 28 (1967), 209-219.

2. A. Pełczynski and W. Szlenk, An example of a non-shrinking basis, Rev. Roumaine Math. Pures Appl. 10 (1965), 961-966.

3. J. R. Retherford, Shrinking bases in Banach spaces, Amer. Math. Monthly $\mathbf{7 3}$ (1966), 841-846.

4. A. Wilansky, The basis in Banach space, Duke Math. J. 18 (1951), 795-798.

Louisiana State University

Received by the editors October 6, 1967.

1 Research supported by NSF GP 5854. 